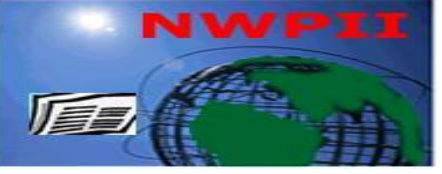

American Journal of Biomedical Sciences

ISSN: 1937-9080

nwpii.com/ajbms

\title{
Nucleophilic Mechanism of ROS/RNS Signaling in Cancer Epigenetic Modifications
}

\author{
Igor Afanas'ev*
}

Vitamin Research Institute, Moscow, Russia

*Corresponding Author:

Professor Igor Afanas'ev

Rua Vitorino Nemesio 48, 6.1, 2050-638

Porto, Portugal

Tel. 351-22-404-1736

E-mail: iafananizer@gmail.com

Received:29 February 2012; | Revised: 1 August 2012; | Accepted: 23 August 2012

\begin{abstract}
It has been shown that cancer is characterized by enhanced oxidative stress. Therefore reactive oxygen and nitrogen species (ROS/RNS) signaling in epigenetic modifications of cancer cells might be even more important comparing to the other pathologies. It is known that ROS/RNS can change DNA methylation through the direct interaction with DNA molecules and by affecting the levels of DNA methyltransferases. ROS/RNS signaling also plays an important role in the mechanism of acetylation/deacetylation of histones by histone acetyltransferases (HAT) and histone deacetylases (HDAC). We suggest that ROS/RNS signaling in epigenetic processes proceeds by a nucleophilic mechanism of etherification and hydrolysis where free radicals superoxide and nitric oxide manifest their nucleophilic properties. As HDAC inhibitors are effective ROS producers, the enhanced oxidative stress might be at least partly responsible for their anticancer activity as epigenetic drugs.
\end{abstract}

Keywords: ROS, RNS, Radicals, Signaling, Cancer.

\section{Introduction}

DNA free radical damage is a widely recognized mechanism of DNA impairment although the structure of free radicals responsible for the attack on DNA molecule remains uncertain. Among free radicals which are supposedly formed in biological systems only hydroxyl radicals are able to abstract hydrogen atoms from biomolecules. However these radicals are very active species and it is unlikely that free hydroxyl radicals can reach DNA molecules. Therefore it has been proposed that hydroxyl radicals might interact with DNA only being formed in its proximity by the reaction of hydrogen peroxide with iron ions (for example with "DNA iron fingers", see below).

At present a new conception of reactive oxygen and nitrogen species (ROS and RNS) 
signaling completely changed our understanding of role of free radicals in biology. It has been shown that ROS and RNS signaling play an important role in many physiological and pathophysiological processes [1]. This conception is a new development of free radical studies in biology which rejects an earlier view on free radicals just as damaging species and considers them the important mediators of biological processes. (It does not mean that being signaling molecules ROS and RNS cannot stimulate damaging processes, but their destructive effects might depend on the initiation of harmful enzymatic processes and not be a consequence of direct interaction with biomolecules).

There are many novel findings which demonstrate ROS and RNS signaling in major epigenetic processes of DNA methylation and histone modification. Importantly that major ROS and RNS are able to participate in these nucleophilic reactions (and not in free radical abstraction reactions). Owing to that a great attention is now attracted to the study their role in various pathologies and particularly in cancer. It does not mean that ROS/RNS signaling is of no importance in normal epigenetic processes but this work will be mostly concerned with epigenetic processes in cancer cells.

\section{ROS/RNS Signaling in Model Epigenetic Systems}

Epigenetics studies alterations in gene expression through the mechanisms other than changes in DNA sequence. Major epigenetic mechanisms include DNA methylation, histone modification, and post transcriptional gene regulation by non-coding microRNAs (miRNAs). At present ROS/RNS signaling has been mostly studied in DNA methylation and histone modification.

\subsection{Mechanisms of ROS/RNS Signaling}

It has already been noted that the involvement of free radicals and their derivatives in epigenetic processes can take place through the reactions of two types: nucleophilic reactions and free radical reactions of hydrogen atom abstraction. Only reactive hydroxyl radicals can abstract hydrogen atoms from biomolecules, while major reactive oxygen (ROS) and nitrogen (RNS) species (paramagnetic free radicals superoxide $\mathrm{O}_{2}{ }^{-*}$ and nitric oxide $\mathrm{NO}$ and their diamagnetic derivatives hydrogen peroxide $\mathrm{H}_{2} \mathrm{O}_{2}$ and peroxynitrite $\mathrm{ONOO}^{-}$) can participate in nucleophilic reactions. We believe that ROS/RNS signaling which will be considered in this work is a very important mechanism of DNA methylation and histone modification.

It is of great importance that ROS and RNS can participate in nucleophilic reactions of etherification and hydrolysis. Thus superoxide is considered to be a "supernucleophile" [2,3] i.e. a very reactive intermediate of hydrolysis and esterification. For example we earlier proposed the mechanism of activation of protein kinases (PKs) by superoxide deprotonation of the serine and threonine residues of proteins [2]:

$\mathrm{HO}\left(\right.$ Ser)X or $\mathrm{HO}(\mathrm{Thr}) \mathrm{X}+2 \mathrm{O}_{2}^{{ }^{-}} \Leftrightarrow$
$\mathrm{O}(\mathrm{Ser}) \mathrm{X}$ or ${ }^{-} \mathrm{O}(\mathrm{Thr}) \mathrm{X}+2 \mathrm{HOO}^{-}$
$\mathrm{PK}-\mathrm{O}($ phos $)+{ }^{-} \mathrm{O}(\mathrm{Ser}) \mathrm{X} \Rightarrow{\mathrm{PK}-\mathrm{O}^{-}+}^{+}$
(phos)O(Ser)X
$\mathrm{PK}-\mathrm{O}\left(\right.$ phos) $+{ }^{-} \mathrm{O}(\mathrm{Thr}) \mathrm{X} \Rightarrow{\mathrm{PK}-\mathrm{O}^{-}+}^{+}$
(phos)O(Thr)X

There are many examples of ROS involvement at the dephosphorylation, deacetylation, and acetylation stages of epigenetic processes. Thus it was found that hyperglycemia insulin-dependent ROS formation influenced multiple histone modifications in myoblasts under hyperglycemic conditions through dephosphorylation and deacetylation of histone H3 [4]. Irradiation of human keratinocytes (NHKs) resulted in the enhancement of ROS formation and the loss of trimethylated histone 3 at Lys27. NHK transduction with BMI1 (polycomb ring finger oncogene) suppressed ROS-mediated effect of irradiation [5]. Similarly ROS produced by etoposide affected histone H2AX phosphorylation in etoposide-treated human lymphoblastoid cells [6]. Elevated levels of H4K12 acetylation depended on increased ROS overproduction during porcine oocyte aging in vitro [7]. Several examples of ROS induction of phosphorylation and acetylation stages are presented in Figure 1. Unfortunately it is uncertain 
whether ROS accelerate or reduce these nucleophilic processes although the increased
ROS levels certainly enhanced H4K12 acetylation in aged porcine oocytes.

\section{ROS $\quad \longrightarrow \quad$ dephosphorylation and deacetylation \\ (hyperglycemia insulin-dependent)}

\section{multiple modifications of histone $\mathrm{H} 3$}

(myoblasts)

[4]

\section{Etoposide

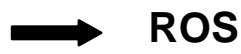 \\ $\rightarrow$ phosphorylation of histone H2AX \\ (human lymphoblastoid cells) \\ ROS

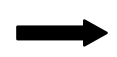 \\ acetylation of histone $\mathrm{H} 4 \mathrm{~K} 12$}

[6]

(porcine oocyte aging)

[7]

Figure 1 ROS signaling on the stages of phosphorylation and acetylation

Some studies suggest that highly reactive hydroxyl radicals can damage DNA molecules. In 1990 Weitzman and Gordon [8] suggested that hydroxyl radicals can induce base modifications through the reactions with thymine glycol, 5hydroxymethyluracil, or 8-hydroxyguanosine. Later on it was found that the formed oxygenated products can affect DNA methylation, for example the methylation of cytosines by hydroxyl free radical adducts on adjacent guanine residues [9]. In subsequent works it has been proposed that hydroxyl radicals damage the DNA methyl-CpG sites $[10,11]$.

Mechanism of hydroxyl radical-mediated DNA damage is uncertain. A direct attack of hydroxyl radical on DNA molecules seems to be very unlikely because these highly reactive radicals cannot reach the cell nucleus due to almost instant reactions with extracellular molecules or the plasma membrane. Probably it is more likely that extracellular hydrogen peroxide, which penetrates efficiently the target cells should be a precursor of hydroxyl radical in DNA proximity.

Many years ago a site-specific mechanism of hydroxyl radical formation in biological systems has been proposed [12]. In accord with this mechanism hydrogen peroxide decomposes to hydroxyl radicals by iron ions bound to biomolecules. Later on it was suggested that due to the close proximity of the zinc finger to DNA, iron-substituted zinc fingers may be the centers of hydroxyl radical formation [13]. Thus site-specific formation of hydroxyl radicals can lead to the formation of DNA free radical adducts.

\subsection{ROS/RNS Signaling in DNA Methylation}

ROS can directly or indirectly induce DNA methylation. For example it has been shown [14] that hydrogen peroxide can affect genome methylation in human premature senescent embryonic lung fibroblasts. Level of genome methylation decreased during hydrogen peroxideinduced premature senescence which was 
associated with the decreased expression of methyltransferase DNMT1. Oncogenic X protein of hepatitis B virus ( $\mathrm{HBx}$ ) suppressed hydrogen peroxide-induced premature cellular senescence in human hepatoma cells through DNA hypermethylation of tumor suppressor protein $\mathrm{p} 16$ (INK4a) promoter [15]. Decrease in global DNA methylation and the inhibition of DNA methyltransferases in rat embryonic neural stem cells (NSCs) exposed to the synthetic glucocorticoid dexamethasone (Dex) depended on ROS formation. It has been demonstrated by exposure of cells to superoxide generator 2,3dimethoxy-1-naphthoquinone (DMNQ) [16]. It was found [17] that the proliferation of Jurkat cells was inhibited by anti-neoplastic drug thymoquinone (TQ). TQ treatment triggered ROS production and apoptosis and downregulated DNA (cytosine-5)-methyltransferase 1(DNMT1) and histone deacetylase 1 (HDAC1). These findings presented in Figure 2 together with data for the effects of ROS on DNA methylation in cancer cells which will be considered below.

$\mathrm{H}_{2} \mathrm{O}_{2} \longrightarrow$ genome methylation $\downarrow \rightarrow$ DNMT1 $\downarrow$

premature senescent human embryonic lung fibroblasts

2,3-dimethoxy-1-naphthoquinone $\rightarrow \mathrm{O}_{2} \cdot \rightarrow$

global DNA methylation $\downarrow$, DNMTs $\downarrow$

rat embryonic neutral stem cells

ROS $\longrightarrow$ global DNA methylation $\downarrow \rightarrow$ DMNT $\downarrow$

prostate tissues

[68]

ROS $\rightarrow$ hypermethylation of E-cadherin promoter $\rightarrow$

DNA methylation by DMNT1

hepatocellular carcinoma

[69]

ROS $\rightarrow$ modulation of DNA methylation

melanoma anchorage blockade

[70]

\section{H. pylori-induced NO $\rightarrow$ methylation of cancer suppression gene \\ epithelial cells \\ [71]}

Figure 2 ROS/RNS-induced DNA methylation 


\subsection{ROS/RNS Signaling in Histone Modification}

Acetylation of lysine residues on the Nterminal tail of core histones by histone acetyltransferases (HAT) results in uncoiling of the DNA. In contrast, histone deacetylation by histone deacetylases (HDAC) suppresses gene transcription by the induction of DNA winding. Both processes are linked and are very important in chromatin remodeling. ROS participate in the regulation of histone acetylation and deacetylation by HATs and HDACs and in the competition between HATs and HDACs.

It has already been demonstrated that ROS can initiate the nucleophilic stages of histone acetylation and phosphorylation (Figure 1). Nitric oxide can also participate in histone modification. A brief treatment of human B-lymphoblastoid cells with nitric oxide-releasing acetylsalicylic acid (NO-ASA) led to histone H2AX phosphorylation on Ser139. NO-ASA also produced ROS which induced H2AX phosphorylation during DNA replication [18].

However the effects of ROS and RNS on histone modification are very complicated. In 2002 Rahman et al. [19] found that hydrogen peroxide and the pro-inflammatory mediator TNF$\alpha$ induced histone acetylation and increased the activation of transcription factors NF- $\kappa \mathrm{B}$ and APlin alveolar epithelial cells. Later on these authors investigated effects of environmental particles with a diameter of $<10 \mu \mathrm{m}$ (PM 10) and hydrogen peroxide on human lung alveolar-like epithelial cells [20]. It was found that PM 10 and hydrogen peroxide co-treatment increased HAT activity in the acetylation of histone 4 (H4). PM 10-enhanced $\mathrm{H} 4$ acetylation depended on the level of oxidative stress and was inhibited by thiol antioxidants.

Hydrogen peroxide was also able to increase histone acetylation and HAT activation [21]. Enhanced oxidative stress leads to an imbalance of HAT and HDAC stoichiometry and contributed to the heightened inflammatory response in the cystic fibrosis $(\mathrm{CF})$ airway. It was proposed that ROS overproduction induced increased acetylation of inflammatory gene promoters in CF airways. It was also found that Ang II inhibited transcriptional activities of PGC$1 \alpha$ (peroxisome proliferator-activated receptor gamma coactivator 1-alpha) through ROSdependent Akt-mediated phosphorylation at Ser570 [22]. Phosphorylation is apparently required for the binding of GCN5 HAT to PGC$1 \alpha$ and its lysine acetylation with subsequent downregulation of catalase expression and increased ROS levels and hypertrophy in VSMCs [23].

Aforementioned data indicate that ROS are able to enhance histone acetylation catalyzed by acetyltransferases. In contrast conflicting findings were reported in literature. ROS production increased during exposure of cells to nickel ions enhancing the inhibition of histone acetylation. $\mathrm{Ni}^{2+}$ ions induced histone hypoacetylation through ROS-dependent suppression of HAT activity and the inhibition of HAT interaction with histones [24]. It has been shown that the treatment of human hepatoma cells with curcumin (Cur) (dietary pigment derived from Curcuma longa) led to a significant ROS-dependent HAT-catalyzed decrease in histone acetylation [25]. The HAT inhibitor chaetocin suppressed methyltransferase SUV39H1through lysine 9 trimethylation on histone $\mathrm{H} 3$ and induced apoptosis in leukemia cells by a ROS-dependent mechanism [26]. All these conflicting data are presented in Figure 3.

\subsection{ROS Signaling in the Class III histone deacetylases}

ROS signaling is particularly important in the catalysis by the class III histone deacetylases Sirt $1 / 3$ belonging to the family of Sirtuin proteins. In addition to their HDAC activity Sirt1/3 play an important role in many ROS-dependent gene/enzyme cascades under physiological and pathophysiological conditions [27-29]. Owing to principal role of Sirt1/3 in many biological processes we will consider some of them in this work.

Sirt $1 / 3$ apparently possesses antioxidant functions. Thus it has been proposed that Sirt3 inhibited ROS formation through the deacetylation and activation of important mitochondrial superoxide dismutase MnSOD [30] (see, also Part 2.6). Chen et al. [31] investigated the mechanism of Sirt3-dependent MnSOD activation. They confirmed that the acetylation at Lys68 decreased MnSOD activity. Mitochondrial Sirt3 formed a 
complex with MnSOD which was responsible for the deacetylation and activation of MnSOD. At the same time an increase in ROS levels stimulated Sirt3 transcription and enhances further the deacetylation and activation of MnSOD. The mitochondrial sirtuin Sirt3 can also act as the tumor suppressor reducing ROS formation and regulating hypoxia inducible factor $1 \alpha$ (HIF-1 $\alpha)$ [32].

\section{$\mathrm{H}_{2} \mathrm{O}_{2}+\mathrm{PM} 10 \longrightarrow \mathrm{ROS} \uparrow \rightarrow \mathrm{HAT} \uparrow \rightarrow$ histone $\mathrm{H} 4$ acetylation $\uparrow$}

$\mathrm{H}_{2} \mathrm{O}_{2} \rightarrow$ HAT $\uparrow \rightarrow$ histone $\mathrm{H} 4$ acetylation $\uparrow$

ROS $\uparrow \rightarrow$ HAT/HDAC imbalance

[22]

Ni ions $\rightarrow$ ROS $\uparrow \rightarrow$ HAT $\downarrow \rightarrow$ histone acetylation $\downarrow$

Curcumin $\rightarrow$ ROS $\rightarrow$ HAT $\downarrow \rightarrow$ histone acetylation $\downarrow$

(human hepatoma cells)

\section{Chaetocin $\longrightarrow$ ROS $\uparrow \rightarrow$ SUV39H1 (HAT) $\downarrow \rightarrow$}

\section{histone $\mathrm{H}_{3} \mathrm{Me}_{3}$ trimethlation $\longrightarrow$ Leukemia cell apoptosis}

Figure 3 Contradictory effects of ROS on histone acetylation by HAT and HDAC

Overexpression of Sirt1 suppressed ROS formation produced by the adaptor protein p66Shc and inhibited high glucose-induced p66Shc upregulation in human umbilical vein endothelial cells. It was suggested that Sirt1suppressed the acetylation of histone $\mathrm{H} 3$ bound to p66Shc promoter region [33]. Sirt1 was apparently able to mediate antioxidative and anti-inflammatory vascular effects of caloric restriction (CR) [34]. Sirt1 mediated vasodilation in vasculature through eNOS-derived nitric oxide formation and ROS suppression enhancing the effects of caloric restriction on lifespan and depression of atherosclerosis [35]. It was found that Sirt1 enhanced transcription of the gene encoding Rictor (a component of mTOR complex 2) triggering the phosphorylation of Akt kinase and FOXO1 and decreasing transcription of the gluconeogenic genes glucose-6-phosphatase and phosphoenolpyruvate carboxykinase [36]. Sirt1 deficiency in liver caused hepatic glucose overproduction, chronic hyperglycemia, and an increase in ROS production that led to insulin resistance.

Sirt3 protected the mouse heart by blocking the cardiac hypertrophic response through the activation of FOXO3a-dependent genes $M n S O D$ and catalase (Cat) and decreasing ROS formation. Reduction of ROS levels suppressed Ras activation and downstream signaling through the MAPK/ERK and PI3K/Akt pathways [37]. $\quad$ Sirt3 is found in neurons where it plays an important role in neuron survival under NMDA-induced excitotoxicity [38]. Sirt1 inhibited superoxide production in endothelial cells and reduced NF- $\kappa \mathrm{B}$-dependent expression of inflammatory adhesion molecules. It has been proposed that Sirt1 activation may prevent atherosclerosis and other inflammatory diseases through the inhibition of superoxide production [39]. 
Sirt1 protein expression but not its transcript level can be downregulated by ROS formed during ionizing radiation (IR) of articular chondrocytes [40]. ROS formation also activated p38 kinase, which further promoted ROS overproduction, forming a positive feedback loop to sustain ROS-p38 signaling. Post-transcriptional Sirt1cleavage occurred due to binding to p38 kinase. It was proposed that IR induced cellular senescence of articular chondrocytes by negative posttranslational regulation of Sirt1 via ROSdependent p38 kinase activation.

Sirt3 functions as a downstream target gene of PGC-1 $\alpha$ (peroxisome proliferatoractivated receptor $\gamma$ coactivator- $1 \alpha$ ) and mediates PGC-1 $\alpha$ effects on ROS production in muscle cells and hepatocytes [41]. Methylenetetrahydrofolate reductase (Mthfr) deficiency in endothelial progenitor cells induced cellular senescence through increased ROS production, reduced nitric oxide generation due to eNOS uncoupling, and downregulation of
Sirt1[42]. The effect of nitric oxide on FOXO1 and Sirt1 genes in $\beta$-cells has also been studied [43]. In response to nitric oxide, FOXO1 translocated from the cytoplasm to the nucleus and stimulated the FOXO1-dependent DNA repair. FOXO1-dependent gene expression was regulated by Sirt1 and the inhibition of Sirt1 induced FOXO1-depended apoptosis.

\subsection{Nitric Oxide Signaling in Histone Deacetylases}

It has already been shown that Sirt1/3 activities can be regulated by nitric oxide [35, 43], but NO is also able to regulate the other HDACs. Signaling functions of the free radical nitric oxide differ from other ROS. Nitric oxide accomplishes numerous physiological functions (for example NO is the endothelium-derived relaxing factor (EDRF)) and capable of activating and inactivating many protein kinases and phosphatases [1].
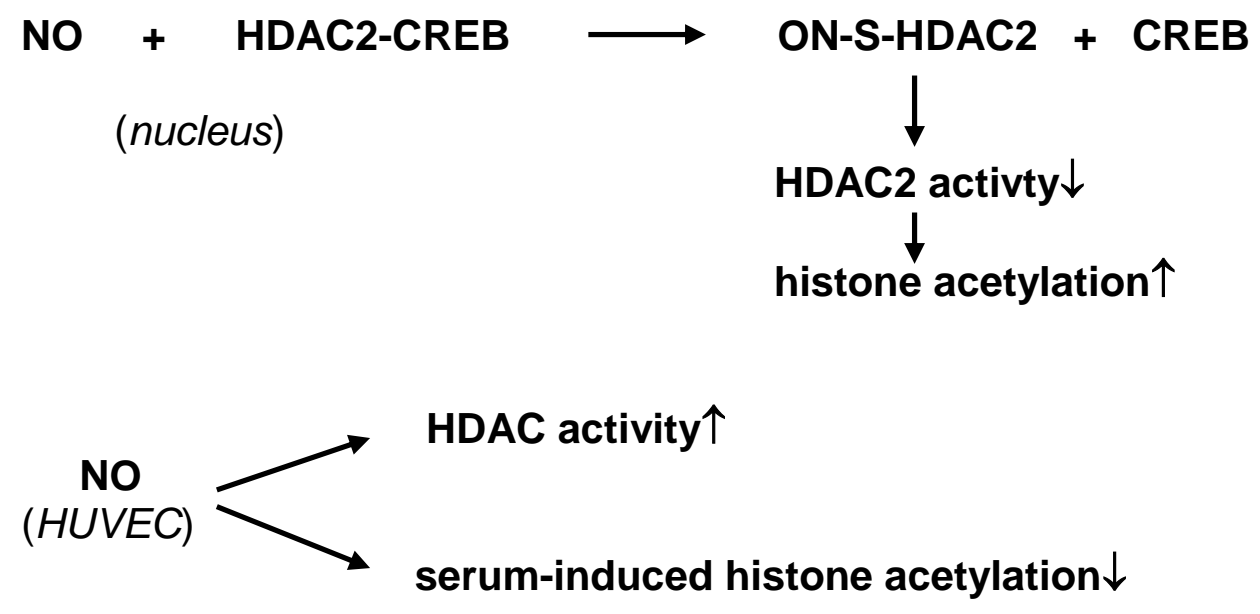

Figure 4 Nitric oxide signaling in histone deacetylases

Histone modification can also depend on NO signaling. Nott and Ricco [44] summarized effects of NO signaling in gene remodeling. Nitric oxide is accumulated within the nucleus and then S-nitrosylates histone deacetylase 2 (HDAC2) which is a key nuclear target for NO attack. HDAC2 $S$-nitrosylation results in the dissociation of HDAC2 deacetylase from transcription factor
(CREB)-regulated gene promoters. This event leads to an increase in histone acetylation at specific promoter regions and transcription of many genes. NO-dependent inhibition of HDAC2 function has been shown in neurons, muscle cells, and other cells. In the other work of these authors [45] it has been shown that brain-derived neurotrophic factor (BDNF) stimulated NO 
formation and S-nitrosylation of histone deacetylase 2 (HDAC2) in neurons inducing histone modifications. S-Nitrosylation of HDAC2 occurred at Cys262 and Cys274 and was not affected deacetylase activity but induced its release from chromatin and promoted transcription [45].

Nitric oxide modulated functions and gene expression in human umbilical vein cells (HUVECs) through the inhibition of seruminduced histone acetylation and the enhancement of histone deacetylase (HDAC) activity [46]. In subsequent work the same authors confirmed that nitric oxide activated class IIa histone deacetylases (HDACs) and induced histone deacetylation in human endothelial cells [47]. Abnormal levels of global histone modification (including Ser10 phosphorylation, the acetylation of Lys9 and Lys 14, and the methylation of Lys79) in skeletal muscle nuclei of $\mathrm{mdx}$ mice and Duchenne muscular dystrophy (DMD) patients have been shown [48]. It was found that nitric oxide reversed the abnormal pattern of $\mathrm{H} 3$ histone modifications. It is obvious that the effects of nitric oxide on histone modification are mixed. As is seen from Figure 4, they depend on cellular systems and can diminish or increase HDAC activity and histone acetylation.

\subsection{Epigenetic Regulation of Antioxidant and Prooxidant Enzymes}

Important mechanisms of ROS signaling in epigenetic processes are the regulation of genes of antioxidant and prooxidant enzymes. This mechanism is of utmost importance for cancer cells which express lower levels of manganese superoxide dismutase (MnSOD) than their normal counterparts. For example it was found that many breast cancer cells exhibited lower expression of MnSOD gene (SOD2) probably due to a defect in the transcription of the gene encoding SOD2. It has been proposed that the difference in SOD2 expression between cancer and normal cells can be caused by distinction in cytosine methylation patterns on the $\mathrm{CpG}$ island. Therefore the association between increased cytosine methylation of the SOD2 intron 2 region and decreased MnSOD expression in cancer cells can be explained by epigenetic mechanism [49]. SOD2 gene was also epigenetically silenced in the human multiple myeloma cells due to promoter hypermethylation [50].

\section{Suppression of SOD2 gene in cancer cells (human multiple myeloma, breast cancer, pancreatic carcinoma)}

Increase in cytosine methylation at SOD2 intron 2

Hypermethylation of promoter in SOD2 gene

CpG methylation, cytosine methylation, and decreased levels of acetylated histones in SOD2 promoter

Decreased levels of dimethyl H3K4 and acetylated H3K9

Methylated sod2 locus

\section{Diabetic retinopathy}

Increase in trimethyl histone $\mathrm{H} 4$

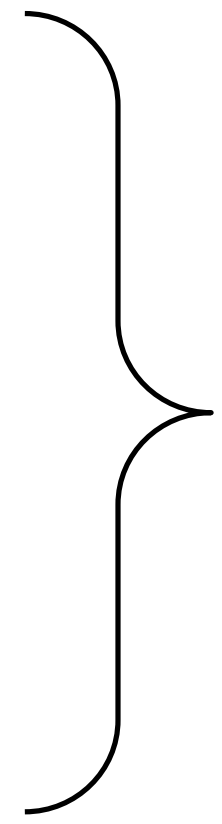

SOD2 $\downarrow$

Figure 5 Epigenetic Regulation of MnSOD 
Epigenetic mechanism of decreased MnSOD activity in malignant breast cancer cells might depend on SOD2 gene suppression by DNA methylation and histone acetylation. Thus higher levels of $\mathrm{CpG}$ methylation in human breast carcinoma cells were found due to increased cytosine methylation which accompanied by significant decrease in the level of acetylated histones in the same region of the SOD2 promoter [51]. In subsequent work it has been shown that decreased levels of histones dimethyl H3K4 and acetylated $\mathrm{H} 3 \mathrm{~K} 9$ stimulated repressive chromatin structure at the SOD2 gene [52]. On the whole, these findings indicate that epigenetic silencing of SOD2 could be initiated by changes in histone modifications and characterize the mechanism leading to the altered expression of MnSOD observed in many breast cancers.

The expression and activity of SOD2 were also reduced in pulmonary artery smooth muscle cells (PASMC) from patients and fawn-hooded rats (FHRs) with hypertension (PAH) [53]. It was suggested that epigenetic SOD2 deficiency initiated hypertension by impairing ROS signaling and creating a proliferative, apoptosis-resistant PASMC. MnSOD augmentation also suppressed experimental $\mathrm{PAH}$. Increase in trimethyl histone $\mathrm{H} 4$ lysine20 (H4K20me3) in MnSOD2 gene contributed to its downregulation and was important for the development of diabetic retinopathy [54]. It was found that the sod2 locus was methylated in pancreatic carcinoma cells leading to a decrease in SOD2 expression. Methyltransferase inhibition by zebularine retrieved SOD2 expression [55]. These data are presented in Figure 5.

Extracellular superoxide dismutase (ECSOD) protects arteries against the deleterious effects of superoxide and the development of atherosclerosis. Reduction of methylated $\mathrm{CpG}$ dinucleotides in ec-sod gene in atherosclerotic aortas was compared to normal aortic intimamedia [56]. While comparison of alterations in DNA methylation in cancer is well characterized, methylation changes in atherosclerosis still are not sufficiently studied even though excess cellular proliferation and alterations in gene expression are typical for both diseases. For example hypomethylation in atherosclerotic aortas occurred at the same level as in malignant tumors; therefore EC-SOD hypomethylation might be associated with the development of atherosclerosis. EC-SOD cell-specific and IFN- $\gamma$ inducible expression in pulmonary artery cells was mainly regulated by epigenetic mechanisms which included histone acetylation and DNA methylation [57].

Epigenetic regulation of superoxidegenerating system (NADPH oxidase) has been studied in leukocytes. It was found that the important histone acetyltransferase GCN5 preferentially elevated the acetylation of H2BK16 and $\mathrm{H} 3 \mathrm{~K} 9$ histones during transcriptional regulation of gp91-phox gene [58].

ROS/RNS participation in epigenetic regulation of inducible NO synthase iNOS was also investigated and histone acetylation in interleukin IL-1 $\beta$-mediated iNOS induction in cultured murine mesangial cells has been studied. It was demonstrated that IL- $1 \beta$-induced iNOS transcription depended on histone $\mathrm{H} 4$ acetylation through phosphoinositide 3-kinase- and p70s6 kinase-dependent pathways [59,60]. Levels of acetylated histones $\mathrm{H} 3$ and $\mathrm{H} 4$ on the proximal promoter of eNOS gene in pulmonary vascular endothelial cells from newborn rats with persistent pulmonary hypertension (PPHN) were significantly higher than those from the control group. These changes of eNOS gene promoter were consistent with increased levels of eNOS mRNA and protein in PPHN [61].

Expression of antioxidant enzyme glutathione peroxidase 3 (GPX3) was downregulated in both rat and human endometrial adenocarcinoma (EAC). Methylation of Gpx3 promoter reached $91 \%$ and the production of hydrogen peroxide was higher in EAC due to downregulated Gpx3 expression [62].

ROS induced the methylation of $\mathrm{CpG}$ island II on the catalase promoter and downregulated catalase expression at the transcriptional level in hepatocellular carcinoma (HCC) cells [63]. POU domain transcription factor Oct-1 and catalase are closely associated with ROS. Oct- 1 acts as the activator of catalase, by 
binding to the catalase promoter in hepatocellular carcinoma (HCC) cells. It was suggested that Oct1 was downregulated by $\mathrm{ROS}$ via $\mathrm{CpG}$ island methylation on its promoter [64].

\section{ROS/RNS-Dependent Epigenetic Processes in Cancer}

Earlier important role of epigenetic processes in cancer has been pointed out by Feinberg et al. [101]. Later studies demonstrated that cancer cells were characterized by altered epigenetic processes comparing to the tissues from which they arise [65]. At present it became clear that the role of oxidative stress (redox processes) in epigenetic modifications in cancer was of some importance [102, 103].

Epigenetic switch in cancer cells can be mainly summarized as changes in both DNA methylation and histone modifications. Irregularities in DNA methylation patterns are an important characteristic of human cancer: it has been found that hypermethylation of $\mathrm{CpG}$ islands of tumor suppressor genes associated with their transcriptional silencing. Another important stage in tumor initiation and progression is histone hypoacetylation which is termed a "cancer signature. $^{\text {.e }}$

At present numerous works demonstrated ROS and RNS signaling in cancer. At the same time many important findings suggest the possibility of application of HAT and HDAC inhibitors as anticancer drugs. It is now wellestablished that cancer cells are characterized by the enhanced oxidative stress (ROS overproduction). Earlier we proposed that both

\footnotetext{
${ }^{1}$ In these studies the participation of redox processes in epigenetics is mainly suggested in the reactions catalyzed by Fe(II)-dependent enzymes. For example it has been proposed that $\mathrm{Fe}$ (II) complexes reduce dioxygen (molecular oxygen) into superoxide which is able to oxidize 2-oxyglutarate [104]. However such hypothetic reactions of superoxide are unknown. Firstly, it is thermodynamically impossible to reduce dioxygen into superoxide by one-electron transfer mechanism with participation of $\mathrm{Fe}$ (II) ions; secondary, the addition reactions of superoxide to the $\mathrm{C}=\mathrm{O}$ bond are unknown. Only nucleophilic substitution reactions of superoxide are of importance.
}

antioxidant and prooxidant compounds might be applied for anticancer treatment: antioxidants for decreasing ROS production in attempt to transform cancer cells in normal ones and prooxidants for destroying cancer cells by ROS overproduction and apoptotic death [66]. However potential anticancer drugs are mostly prooxidants, therefore apoptosis is apparently a much more efficient way for fighting cancer.

\subsection{ROS/RNS-Dependent DNA Methylation in Cancer}

We are already considered the regulation of DNA methylation through ROS/RNS signaling: ROS-dependent DNA methylation is definitely a very important process in cancer cells (Figure 2). For example ROS producers NADPH oxidases DUOX1 and DUOX2 can be silenced in human lung cancer by hypermethylation of CpG-rich promoter regions in both DUOX genes, i.e. ROS formation can be suppressed by an epigenetic mechanism in cancer [67]. Increased ROS formation and DNA methylation were observed in many malignant processes including prostate cancer. For example ROS overproduction inhibited DNA methyltransferase and decreased global DNA methylation in prostate tissues of CuZnSOD knockdown mice [68].

Hypermethylation of transmembrane protein E-cadherin promoter in hepatocellular carcinoma stimulated ROS formation causing DNA methylation by DNA methyltransferase 1[69]. ROS modulated DNA methylation levels during melanoma anchorage blockade and affected anoikis (apoptosis induced by loss of appropriate cell-matrix contact) through epigenetic mechanism [70].

Nitric oxide can also stimulate DNA methylation. For example Katayama et al. [71] investigated epigenetic changes in some cancer suppression genes by helicobacter pylori $(\mathrm{H}$. pylori). They demonstrated that $\mathrm{H}$. pylori induced NO formation in macrophages and that NO caused methylation of the cancer suppression gene runx 3 in epithelial cells.

Nucleoside DNMT inhibitors decitabine and zebularine stimulated mitochondrial alterations and ROS-dependent apoptosis in leukemic $\mathrm{T}$ cells [72]. Oxidative stress initiated 
arsenic-induced neural tube defects (NTDs) in chick embryos [73]. Arsenic exposure increased intracellular ROS and changed DNA methylation. A decrease in MnSOD activity and significant decrease in DNA methyltransferase (DNMT1/3a) expression were also observed after arsenic exposure. 3-Deazaneplanocin A (DZNep), a histone methyltransferase inhibitor, disrupted polycomb-repressive complex 2 (PRC2) and preferentially induced apoptosis in acute myeloid leukemia (AML) by the ROS-mediated reactivation of thioredoxin-interacting protein TXNIP and inhibition of thioredoxin activity [74].

\subsection{ROS-Dependent Histone Acetylation in Cancer}

Histone deacetylase inhibitors (HDACi) induced hyperacetylation of core histones modulating chromatin structure and affecting gene expression. These compounds also induced growth arrest, cell differentiation, and apoptotic cell death of tumor cells in vitro and in vivo. It has been shown above that ROS signaling is particularly important for the activity of the class III histone deacetylases Sirt1/3. Functions of histone deacetylases Sirt1/3 in cancer are uncertain. It was found that levels of Sirt3 protein decreased in human breast and other cancers probably due the localization of Sirt3 in mitochondria [75].

The inhibition of histone deacetylase HDAC10 led to ROS formation, release of cytochrome c, and the activation of apoptosis in human gastric cancer cells [76]. Ethanol treatment upregulated HDAC2 through ROS overproduction in human neuronal cells that might play an important role in alcohol use disorders [77]. In contrast numerous studies show that ROS inhibited histone deacetylases and that the activity of HDAC inhibitors depended on their ability to generate ROS. It has been proposed that the antitumor effects of HDAC inhibitors derived from the accumulation of acetylated histones, enhanced ROS generation, and subsequent apoptosis [78]. Numerous inhibitors of histone deacetylases (HDACi) are now developed for treatment of cancer and other pathologies [79] (Figure 6)

The HDAC inhibitor suberoylanilide hydroxamic acid (SAHA) induced cell death by the release of mitochondrial cytochrome $c$ and an increase in ROS production [80]. The HDAC inhibitor MS-275 (Entinostat) exhibited the dosedependent effects in human leukemia cells inducing growth arrest and differentiation at low concentrations and ROS overproduction, mitochondrial damage, caspase activation, and apoptosis at higher concentrations [81]. In nonproliferating chronic lymphocytic leukemia (CLL) cells MS-275 enhanced ROS formation and induced acetylation of histones $\mathrm{H} 3$ and $\mathrm{H} 4$. However in contrast to previous reports decreased HDAC activity and ROS formation did not precede apoptosis [82]. PCI-24781, a novel hydroxamic acid-based HDAC inhibitor induced histone H3 alterations, enhanced superoxide formation, and stimulated apoptosis in acute leukemia cells through the activation of caspase- 8 and FADD [83]. HDAC inhibitor M344 inhibited cell proliferation and induced apoptosis in human leukemia cells [105].

To enhance the prooxidant activities of HDACi the combinations of HDACi with different anticancer drugs have been developed. Thus exposure of the combination of proteasome inhibitor bortezomib with histone deacetylase inhibitors sodium butyrate and SAHA to human multiple myeloma (MM) cells sharply enhanced ROS-dependent mitochondrial dysfunction and apoptosis in these cells [84]. Oral squamous cell carcinoma cells were treated with several HDAC inhibitors: sodium butyrate, SAHA, and MS-275 together with cisplatin. HDAC inhibitors increased ROS generation, activated caspase-3, and enhanced apoptosis in carcinoma cells [85]. Combination of HDAC inhibitor LAQ824 with 13-cis-retinoic acid (CRA) was used for the treatment of human melanoma cells under in vitro and in vivo conditions. It was found that the induction of apoptosis by LAQ824 depended on increased ROS formation [86].

Combination of the new proteasome inhibitor NPI-0052 with NDAC inhibitors MS-275 or valproic acid (VPA) induced enhanced ROS generation and greater levels of leukemia cell death than the combination of bortezomib with the same histone deacetylase inhibitors [87]. Later on it has been confirmed that the combination of histone deacetylase and proteasome inhibitors 
stimulated histone $\mathrm{H} 3$ expression and acetylation through ROS-dependent mechanism in leukemia cells [88]. Strong ROS-dependent anticancer activity of combination of HDAC inhibitor trichostatin A (TSA) with nucleoside analog gemcitabine (GEM) was observed against pancreatic cancer cells under in vitro and in vivo conditions [89].

\section{HUMAN NEUTROPHILS}

Ethanol treatment $\longrightarrow \operatorname{ROS} \uparrow \longrightarrow \operatorname{HDAC} 2 \uparrow$

\section{LEUKEMIA CELLS}

$\mathrm{SAHA} \longrightarrow \mathrm{ROS} \uparrow \longrightarrow$ cytochrome c release $\longrightarrow$ cell death

MS-275 (low concentrations) $\rightarrow$ growth arrest and differentiation

MS-275 (high concentrations) $\longrightarrow$ ROS $\longrightarrow$ apoptosis

$\mathrm{PCl}-24781 \longrightarrow \mathrm{O}_{2}^{-` \uparrow} \longrightarrow$ apoptosis

NPI-0052 (proteasome inhibitor) + HDAC inhibitors $\longrightarrow$ ROS $\uparrow$

$\longrightarrow$ histone $\mathrm{H} 3$ expression + acetylation

MS-275 or SAHA $\rightarrow$ hyperacetylation $\longrightarrow$ ROS $\uparrow \rightarrow$ cell death

SAHA or sodium butyrate + PD184352 (MEK kinase inhibitor) $\rightarrow$ ROS $\uparrow$

$\rightarrow$ apoptosis

2-methoxyestradiol + HDAC inhibitors $\rightarrow$ ROS $\uparrow \rightarrow$ cytochrome c release

$\rightarrow$ apoptosis

AEE788 (tyrosine kinase inhibitor) + HDAC inhibitors $\rightarrow$

$\operatorname{ROS} \uparrow \rightarrow$ apoptosis

LYMPHOCYCTIC LEUKEMIA CELLS

MS-275 $\longrightarrow$ ROS $\uparrow \longrightarrow$ histones $\mathrm{H} 3 / \mathrm{H} 4$ acetylation

MULTIPLE MYELOMA CELLS

Bortezomib (proteasome inhibitor) + HDAC inhibitors $\longrightarrow$ ROS $\uparrow$

$\longrightarrow$ apoptosis

ORAL SQUAMOUS CELL CARCINOMA CELLS 
Sodium butyrate + SAHA + MS- 275 + cisplatin $\longrightarrow$ ROS $\uparrow \longrightarrow$

apoptosis

HUMAN MELANOMA CELLS

LAQ824 +13-cis-retinoic acid $\longrightarrow$ ROS $\rightarrow$ apoptosis

[86]

PANCREATIC CANCER CELLS

Trichostatin A + gemcitabine (nucleoside analog) $\rightarrow \operatorname{ROS} \uparrow \rightarrow$

cell death

[89]

NON-SMALL CELL LUNG CANCER CELLS

SAHA + sulindac (anti-inflammatory drug) $\longrightarrow \operatorname{ROS} \uparrow \rightarrow$

cell death

[90]

MALIGNANT MESOTHELIOMA CELLS

Valproate + cisplatin $\longrightarrow \operatorname{ROS} \uparrow \longrightarrow$ apoptosis

Carfilzomib (proteasome inhibitor) + HDAC inhibitors $\rightarrow$ ROS $\uparrow$

$\rightarrow$ apoptosis of mantel cell lymphoma cells

$\mathrm{PCl}-24781$ + bortezomib(proteasome inhibitor) $\rightarrow$ ROS $\rightarrow$

apoptosis of Hodgkin lymphoma and non-Hodgkin lymphoma cells

3'-Me-Ado(ribonucleotide reductase inhibitor) + HDAC inhibitors

ROS $\rightarrow$ apoptosis of promyelocytic leukemia cells.

Figure 6 ROS-dependent effects of HDAC inhibitors

Sulindac (a non-steroidal antiinflammatory drug) significantly enhanced SAHA-induced growth suppression and apoptosis of human non-small cell lung cancer cells through the ROS-dependent release of cytochrome $\mathrm{c}$ and caspase activation [90]. Valproate (HDAC inhibitor) increased the anticancer efficacy of cisplatin and pemetrexed in the treatment of malignant mesothelioma through the enhancement of ROS formation and the induction of apoptosis [91]. HDAC inhibitors vorinostat or entinostat increased the lethality of the dual Bcr/Abl-Aurora kinase inhibitor KW-2449 in human leukemia cells [92]. HDAC inhibitors MS-275 and SAHA activated NF- $\mathrm{\kappa B}$ and induced hyperacetylation and nuclear translocation of RelA/p65 in leukemia 
cells. This process accompanied by ROS overproduction, downregulation of $\mathrm{MnSOD}$, and JNK1 MAP kinase activation. These findings suggested that HDAC inhibitors enhanced cell lethality through ROS overproduction [93].

Role of ROS production in DNA damage and potentiation of fludarabine lethality by the histone deacetylase inhibitor LAQ-824 has been studied in human leukemia cells [94]. It was found that the combination of LAQ-824 with fludarabine dramatically enhanced apoptosis and triggered an early ROS formation that followed LAQ-824induced MnSOD upregulation. Application of combination of multiple receptor tyrosine kinase inhibitor AEE788 with histone deacetylase inhibitors LBH589, LAQ824, and trichostatin A resulted in synergistic induction of apoptosis in non-small cell lung cancer, ovarian cancer, and leukemia cells. These inhibitors enhanced ROS generation and inactivated enzymatic cascades catalyzed by MAPK and Akt kinases [95].

Co-administration of histone deacetylase inhibitors SAHA or sodium butyrate with PD184352 inhibitor of MEK1/2 kinase to $\mathrm{Bcr} / \mathrm{Abl}+$ human leukemia cells resulted in a synergistic increase in ROS generation, mitochondrial damage, caspase activation, and apoptosis. These events also accompanied by the inactivation of ERK and Akt kinases and the activation of JNK MAP kinase [96]. Coadministration of marginally toxic concentrations of the endogenous estradiol metabolite 2methoxyestradiol (2-ME) with SAHA or sodium butyrate resulted in an increase in ROS formation, cytochrome $c$ release, caspase activation, and apoptosis in human leukemia cells. Synergistic interaction between these inhibitors also led to inactivation of Akt kinase and activation JNK kinase. MnSOD mimetic TBAP and catalase reverted inhibitory effects [97].

Similarly the combinations of HDACi with the inhibitors of other enzymes can be used. Thus it has been shown that co-administration of very low concentrations of the proteasome inhibitor carfilzomib with HDACi vorinostat or SNDX-275 induced a sharp increase in mitochondrial injury and apoptosis in mantle cell lymphoma (MCL) cells. These effects were associated with JNK1/2 activation, ERK1/2 and Akt inactivation, and ROS overproduction [98]. Mechanism of cell death in Hodgkin lymphoma and non-Hodgkin lymphoma cells induced by HDAC inhibitor PCI-24781alone or its combination with proteasome inhibitor bortezomib has been investigated [99]. PCI24781/bortezomib treatment led to strong ROSand caspase-dependent synergistic apoptosis. Meli et al. [100] examined which of the possible combinations of HDAC inhibitors (two recently synthesized compounds MC1864 and MC1879 and trichostatin A (TSA)) with ribonucleotide reductase (RR) inhibitor 3'-C-methyladenosine (3'Me-Ado) would be the most effective and clinically useful in the treatment of promyelocytic leukemia cells. They found significant synergistic effects with all combinations on ROS-dependent cell growth, inhibition, and apoptosis.

\section{Discussion}

Epigenetic changes in cancer cells can be summarized as the changes in both DNA methylation and histone modifications. It was noted that hypermethylation of $\mathrm{CpG}$ islands of tumor suppressor genes associated with their transcriptional silencing and that tumor initiation and progression depended on histone hypoacetylation. We already pointed out that cancer cells are characterized by enhanced oxidative stress [66]. Therefore ROS/RNS signaling in the epigenetic modifications of cancer cells can be even more important than in the other pathologies. It has been shown that at various pathological disorders ROS can modulate DNA methylation through the direct interaction with DNA molecules and by affecting the levels of DNA methyltransferases [14,16]. Analogical ROS/RNS effects were observed in cancer cells [68-70]. Nitric oxide might also stimulate DNA methylation [71] (Figure 2). It is seen that ROS can decrease DNA methylation and suppress DNMT activities. It is interesting that in two different systems (rat embryonic neutral stem cells [16] and prostate tissues [68]) ROS initiates identical epigenetic changes: the suppression of global DNA methylation and the inhibition of DNMTs.

ROS/RNS modify histones under hyperglycemic conditions, during cell irradiation, 
or in the presence of prooxidants [4-6,18]. ROS/RNS also play an important role in the activities of HDAC and HAD inhibitors. Numerous examples of application of HDACi as anticancer drugs have been described [80-100] (Figure 6). It has been found that all these inhibitors (alone or together with the inhibitors of other enzymes or with prooxidants) are ROS producers.

Important mechanism of ROS enhancement by epigenetic regulation is the modification of genes of antioxidant and prooxidant enzymes. This mechanism is even more important for cancer cells which express lower levels of manganese superoxide dismutase (SOD2). It has been proposed that SOD2 gene of MnSOD can be suppressed in cancer cells due to DNA methylation and histone acetylation [51,52]. Suppression of MnSOD has been found in other pathologies such as hypertension and diabetic retinopathy (Figure 5). Similar epigenetic mechanisms have been demonstrated for the suppression of genes of other antioxidant enzymes: extracellular superoxide dismutase (ECSOD), glutathione peroxidase, and catalase as well as for prooxidant enzymes NADPH oxidase and nitric oxide synthase.

How reactive oxygen and nitrogen species initiate epigenetic processes? It is of utmost importance that ROS and RNS regulate gene methylation and acetylation which are heterogeneous nucleophilic reactions. One should expect that such reactions cannot proceed by free radical mechanisms but it is true when we speak about typical free radicals such as hydroxyl radicals. However major ROS and RNS are superoxide, hydrogen peroxide, and nitric oxide which are able to participate in nucleophilic reactions. For example superoxide is a "supernucleophile", a very active mediator of nucleophilic reactions of etherification and hydrolysis [2,3].

As is seen from Figure 1, ROS induce the hydrolysis and etherification/deetherification stages of epigenetic processes. It is seen that hyperglycemia insulin-dependent ROS influenced multiple histone modifications in myoblasts through dephosphorylation and deacetylation of histone H3 [4]. Similarly ROS produced by etoposide affected histone H2AX phosphorylation in etoposide-treated human lymphoblastoid cells [6]. The elevated levels of H4K12 acetylation probably depended on increased ROS overproduction during porcine oocyte aging in vitro [7]. Thus the mechanism of ROS-dependent HDAC inhibition can occur through deetherification by superoxide:

$\mathrm{O}_{2}{ }^{--}+$Ac-O-lysine residues on the $\mathrm{N}$ terminal tail of core histones $\rightarrow$

$$
\mathrm{Ac}^{-}+\text {HO-lysine residues }+\mathrm{O}_{2}
$$

Therefore it can be suggested that ROS and RNS are at least partly responsible for epigenetic changes leading to the development of cancer and other pathologies. ROS/RNS overproduction by HDAC inhibitors might be an effective mechanism of anticancer activity of these compounds.

\section{References}

1- Afanas'ev, I. B. Signaling Mechanisms of Oxygen and Nitrogen Free Radicals; Boca Raton, Florida, 2009; CRC Press, Taylor \& Francis Group, pp 1-201.

2- Afanas'ev, I. B. On mechanism of superoxide signaling under physiological and pathophysiological conditions, Med. Hypotheses, 2005, 64, 127-129. DOI: 10.1016/i.mehy.2004.05.009

3- Afanas'ev, I. B. Competition between superoxide and hydrogen peroxide signaling in heterolytic enzymatic processes, Med. Hypotheses, 2006, 66, 1125-1128. DOI: 10.1016/j.mehy.2005.11.046

4- Kabra, D.G,; Gupta, J; Tikoo K. Insulin induced alteration in post-translational modifications of histone $\mathrm{H} 3$ under a hyperglycemic condition in L6 skeletal muscle myoblasts, Biochim. Biophys. Acta, 2009, 1792, 574-583.

5- Dong, Q.; Oh, J. E.; Chen, W.; Kim.; R, Kim, R. H.; Shin, K. H.; McBride, W. H.; Park, N.; Kang, M. K. Radioprotective effects of BMi1 involve epigenetic silencing of oxidase genes and enhanced DNA repair in normal 
human keratinocytes, Invest. Dermatol, 2011, 131, 1216-1225. DOI: 10.1038/jid.2011.11

6- Tanaka, T.; Halicka, H. D.; Traganos, F.; Seiter, K.; Darzynkiewicz, Z. Induction of ATM activation, histone $\mathrm{H} 2 \mathrm{AX}$ phosphorylation and apoptosis by etoposide: relation to cell cycle phase, Cell Cycle, 2007, 6, 371-376. DOI: $10.4161 /$ cc.6.3.3835

7- Cui, M. S.; Wang, X. L.; Tang, D. W.; Zhang, J.; Liu, Y.; Zeng, S. M. Acetylation of H4K12 in porcine oocytes in vitro aging: potential role of ooplasmic reactive oxygen species, Theriogenology, 2011, 75, 638-646. DOI: 10.1016/j.theriogenology.2010.09.031

8- Weitzman, S. A.; Gordon, L. I. Inflammation and cancer: role of phagocyte-generated oxidants in carcinogenesis, Blood 1990, 76, $655-663$.

9- Weitzman, S. A; Turk, P. W.; Milkowski, D. H.; Kozlowski, K. Free radical adducts induce alterations in DNA cytosine methylation. Proc. Natl. Acad. Sci. USA, 1994, 91, 1261 - 1264. DOI: 10.1073/pnas.91.4.1261

10- Valinluck, V.; Tsai, H-H.; Rogstad, D. K.; Burdzy, A.; Bird, A.; Sowers, L. C. Oxidative damage to methyl-CpG sequences inhibits the binding of the methyl-CpG binding domain (MBD) of methyl-CpG binding protein 2 (MeCP2), Nucleic Acids Res, 2004, 32, 4100 4108. DOI: $10.1093 / \mathrm{nar} / \mathrm{gkh} 739$

11- Cao, H.; Wang, Y. Quantification of oxidative single-base and intrastrand cross-link lesions in unmethylated and CpG-methylatedDNA induced by Fenton-type reagents, Nucleic. Acids Res., 2007, 35, 4833-4844. DOI: 10.1093/nar/gkm497

12- Samuni, A.; Aronovitch, J.; Godinger, D.; Chevion, M.; Czapski, G. On the cytotoxicity of vitamin $\mathrm{C}$ and metal ions. A site-specific Fenton mechanism. EUR J. Biochem.,1983, 137, 119-124. DOI: 10.1111/j.14321033.1983.tb07804.x

13- Conter, D; Narindrasorasak, S.; Sarkar, B. In vivo and in vitro iron-replaced zinc finger generates free radicals and causes DNA damage, J. Biol. Chem.,1996, 271, 51255130. DOI: $10.1074 / \mathrm{jbc} .271 .9 .5125$
14- Zhang, W.; Ji, W.; Yang, J.; Yang, L.; Chen, W.; Zhuang, Z. Comparison of global DNA methylation profiles in replicative versus premature senescence, Life Sci., 2008, 83, 475-480. DOI: 10.1016/j.lfs.2008.07.015

15- Kim, Y. J.; Jung, J. K.; Lee, S.Y.; Jang, K. L. Hepatitis $B$ virus $X$ protein overcomes stressinduced premature senescence by repressing p16(INK4a) expression via DNA methylation, Cancer Lett., 2010, 288, 226235. DOI: 10.1016/j.canlet.2009.07.007

16- Bose, R.; Moors, M.; Tofighi, R.; Cascante, A.; Hermanson, .; Cessatelli, S. Glucocorticoids induce long-lasting effects in neutral stem cells resulting in senescencerelated alterations, Cell Death Dis., 2010,1, e92. DOI: $10.1038 /$ cddis.2010.60

17- Alhosin, M.; Abusnina, A.; Achour, M.; Sharif, T.; Muller, C.; Peluso, J.; Chataigneau, T.; Lugnier, C.; Schini-Kerth, VB.; Bronner, C.; Fuhrmann, G. Induction of apoptosis by a p73-dependent pathway which targets the epigenetic integrator UHRF1, Biochem. Pharmacol., 2010, 79,1251-1260. DOI: 10.1016/j.bcp.2009.12.015

18- Tanaka, T.; Kurose, A.; Halicka, H. D.; Huang, X.; Traganos, F.; Darzynkiewicz, Z. Nitrogen oxide-releasing aspirin induced histone H2AX phosphorylation, ATM activation and apoptosis preferentially in Sphase cells: involvement of reactive oxygen species, Cell Cycle, 2006, 5, 1669-1674. DOI: $10.4161 / \mathrm{cc} .5 .15 .3100$

19- Rahman, I.; Gilmour, P. S.; Jimenez, L. A.; MacNee, W. Oxidative stress and TNF-alpha induce histone acetylation and NFkappaB/AP-1 activation in alveolar epithelial cells: potential mechanism in gene transcription in lung inflammation, Mol. Cell. Biochem., 2002, 234-235, 239-248. DOI: 10.1023/A:1015905010086

20- Gilmour, P. S.; Rahman, I.; Donaldson, K.; MacNee, W. Histone acetylation regulates epithelial IL-8 release mediated by oxidative stress from environmental particles, Am. J. Physiol. Lung Cell Mol. Physiol., 2003, 284, L533-L540.

21- Tomita, K.; Barnes, P.J.; Adcock, I.M. The effect of oxidative stress on histone 
acetylation and IL-8 release, Biochem. Biophys. Res. Commun., 2003, 301, 572-577. DOI: $10.1016 / \mathrm{S} 0006-291 \mathrm{X}(02) 03029-2$

22- Bartling, T.R.; Drumm, M. L. Oxidative stress causes IL8 promoter hyperacetylation in cystic fibrosis airway cell models, Am. J. Respir. Cell Mol. Biol., 2009, 40, 58 - 65. DOI: 10.1165/rcmb.2007-04640C

23- Xiong, S.; Salazar, G.; San Martin, A.; Ahmad, M.; Patrushev, N.; Hilenski, L.; Nazarewicz, R. R.; Ma, M.; Ushio-Fukai,; Alexander, R. W. PGC-1alpha serine 570 phosphorylation and GCN5-mediated acetylation by angiotensin II drive catalase down-regulation and vascular hypertrophy, J. Biol. Chem., 2010, 285, 2474-2487.

24- Kang, J.; Zhang, Y.; Chen, J.; Chen, H.; Lin, C.; Wang, Q.; Ou, Y. Nickel-induced histone hypoacetylation: the role of reactive oxygen species, Toxicol. Sci., 2003, 74, 279-286. DOI: $10.1093 /$ toxsci/kfg137

25- Kang, J.; Chen, J.; Shi, Y.; Jia, J.; Zhang, Y. Curcumin-induced histone hypoacetylation: the role of reactive oxygen species, Biochem. Pharmacol., 2005, 69, 1205-1213.

26- Chaib H, Nebbioso A, Prebet T, Castellano R, Garbit S, Restouin, A.; Vey, N.; Altucci, L.; Collette, Y. Anti-leukemia activity of chaetocin via death receptor-dependent apoptosis and dual modulation of the histone methyl-transferase SUV39H1, Leukemia, 2011. Oct 7. doi: 10.1038/leu.2011.271.

27- Afanas'ev, I. Reactive oxygen species and age-related genes p66Shc, Sirtuin, FoxO3 and Klotho in senescence, Oxid. Med. Cell. Longevity, 2010, 3,1-9.

28- Afanas'ev, I. Signaling of reactive oxygen and nitrogen species in Diabetes mellitus, Oxid. Med. Cell. Longevity, 2010, 3, 361-373. DOI: 10.4161/oxim.3.6.14415

29- Afanas'ev, I. ROS and RNS signaling in heart disorders: could antioxidant treatment be successful? Oxid. Med. Cell. Longevity, Volume 2011 (2011), Article ID 293769, 13 pages.

30- Ozden, O.; Park, S. H.; Kim, H. S.; Jiang, H.; Coleman, M. C.; Spitz, D. R.; Gius, D. Acetylation of MnSOD directs enzymatic activity responding to cellular nutrient status or oxidative stress, Aging (Albany NY), 2011, 3, 102-107.

31- Chen, Y.; Zhang, J.; Lin, Y.; Lei, Q.; Guan, K. L.; Zhao, S.; Xiong, Y. Tumor suppressor SIRT3 deacetylates and activates manganese superoxide dismutase to scavenge ROS, EMBO Rep., 2011,12, 534-541.

32- Bell, E. L.; Emerling, B. M.; Ricoult, S. J.; Guarente, L. SirT3 suppresses hypoxia inducible factor $1 \mathrm{~A}$ and tumor growth by inhibiting mitochondrial ROS production, Oncogene, 2011, 30, 2986-2996. DOI: 10.1038/onc.2011.37

33- Zhou S, Chen HZ, Wan YZ, Zhang QJ, Wei YS, Huang S, Liu, J. J.; Lu, Y. B.; Zhang, Z.Q.; Yang, R. F.; Zhang, R.; Cai, H.; Liu, D. P.; Liang, C. C. Repression of P66Shc expression by SIRT1 contributes to the prevention of hyperglycemia-induced endothelial dysfunction, Circ. Res., 2011, 109, 639 - 648. DOI: 10.1161/CIRCRESAHA. 111.243592

34- Csiszar, A.; Labinskyy, N.; Jimenez, R.; Pinto, J. T.; Ballabh, P.; Losonczy, G.; Pearson, K. J.; de Cabo, R.; Ungvari, Z. Anti-oxidative and anti-inflammatory vasoprotective effects of caloric restriction in aging: role of circulating factors and SIRT1, Mech. Ageing Dev., 2009, 130, 518-527.

35- Stein, S.; Matter, C. M. Protective roles of SIRT1 in atherosclerosis, Cell Cycle, 2011, 10, 640-647. DOI: 10.4161/cc.10.4.14863

36- Wang, R. H.; Kim, H. S.; Xiao, C.; Xu, X.; Gavrilova, O.; Deng, CX. Hepatic Sirt1 deficiency in mice impairs mTorc2/Akt signaling and results in hyperglycemia, oxidative damage and insulin resistance, $J$. Clin. Invest., 2011, Oct3, pii: 46243 [Epub ahead of print]. DOI: 10.1172/JCI46243

37- Sundaresan, N. R.; Gupta, M.; Kim, G.; Rajamohan, S. B.; Isbatan, A.; Gupta, M. P. Sirt3 blocks the cardiac hypertrophic response by augmenting Foxo3a-dependent antioxidant defense mechanisms in mice, J. Clin. Invest., 2009, 119, 2758-2771.

38- Kim, S. H.; Lu, H. F.; Alano, C. C. Neutronal Sirt3 protects against excitotoxic injury in mouse cortical neuron culture, PLoS, 2011, 6, e14731. 
39- Stein S, Schafer N, Breitenstein A, Besler C, Winnik S, Lohmann C, Heinrich, K.; Brokopp, C. E.; Handschin, C.; Landmesser, U.; Tanner, F. C.; Lüscher, T. F.; Matter, C. M. SIRT1 reduces endothelial activation without affecting vascular function in Apo-/mice, Aging (Albany NY), 2010, 2, 353-360.

40- Hong, E. H.; Lee, S. J.; Kim, J. S.; Lee, K. H.; Um, H. D.; Kim, J. H.; Kim, S. J.; Kim, J. I.; Hwang, S.G. Ionizing radiation induces cellular senescence of articular chondrocytes via negative regulation of SIRT1 by $\mathrm{p} 38$ kinase, J. Biol. Chem. 2010, 285, 1283-1295.

41- Kong X, Wang R, Xue Y, Liu X, Chen Y, Fang F, Chang Y. Sirtuin 3, a new target of PGC-1alpha, plats an important role in the suppression of ROS and mitochondrial biogenesis. PLoS One 2010; 5: e11707. DOI: 10.1371/journal.pone.0011707

42- Lemarié, C. A.; Shbat, L.; Marchesi, C.; Angulo, O. J.; Deschênes, M.-E.; Blostein, M. D.; Paradis, P.; Schiffrin, E. L. Mthfr deficiency induces endothelial progenitor cell senescence via uncoupling of eNOS and downregulation of SIRT1, Am. J. Physiol. Heart Circ. Physiol., 2011, 300, H745 H753. DOI: 10.1152/ajpheart.00321.2010

43- Hughes, K. J.; Meares, G. P.; Hansen, P. A.; Corbett, J. A. FoxO1 and SIRT1 regulate $\beta$ cell responses to nitric oxide, J. Biol. Chem., 2011. 286, $8338 \quad$ - 8348. 44- Nott, A.; Ricco, A. Nitric oxide-mediated epigenetic mechanisms in developing neurons, Cell Cycle, 2009, 8, 725-730.

45- Nott, A.; Watson, P. M.; Robinson, J. D.; Crepaldi, L.; Riccio, A. S-Nitrosylation of histone deacetylase 2 induces chromatin remodelling in neurons, Nature, 2008, 455(7211), 411-415.

46- Illi, B.; Dello Russo, C.; Colussi, C.; Rosati, J.; Pallaoro, M.; Spallotta, F.; Rotili, D.; Sergio Valente, S.; Ragone, G.; Martelli, F.; Biglioli, P.; Steinkuhler, C.; Gallinari, P.; Antonello Mai, A.; Capogrossi, M. C.; Gaetano, C. Nitric oxide modulates chromatin folding in human endothelial cells via protein phosphatase $2 \mathrm{~A}$ activation and class II histone deacetylases nuclear shuttling, Circ. Res., 2008, 102, 51 - 58.
47- Spallotta, F.; Rosati, J.; Straino, S.; Nanni, S.; Grasselli, A.; Ambrosino, V.; Rotili, D,; Valente, S.; Farsetti, A.; Mai, A.; Capogrossi, M. C.; Gaerano, C.; Illi, B. Nitric oxide determines mesodermic differentiation of mouse embryonic stem cells by activating class IIa histone deacetylases: potential therapeutic implication in a mouse model of hindlimb ischemia, Stem Cells, 2010, 28, 431442.

48- Colussi, C.; Gurtner, A.; Rosati, J.; Illi, B.; Ragone, G.; Piaggio, G.; Moggio, M.; Lamperti, C.; D’Angelo, G.; Clementi, E.; Minetti, G.; Mozzetta, C.; Antonini, A.; Cappgrossi, M. C.; Puri, P. L.; Gaetano, C. Nitric oxide deficiency determines global chromatin changes in Duchenne muscular dystrophy, FASEB J, 2009, 23, 2131-2141.

49- Huang, Y.; He, T.; Domann, F. E. Decreased expression of manganese superoxide dismutase in transformed cells is associated with increased cytosine methylation of the SOD2 gene, DNA Cell. Biol., 1999, 18, 643652.

50- Hodge, D. R.; Peng, B.; Pompeia, C.; Thomas, S.; Cho, E.; Clausen, P. A.; Marguez, V. E.; Farrar, W. L. Epigenetic silencing of manganese superoxide dismutase (SOD-2) in KAS 6/1 human multiple myeloma cells increases cell proliferation, Cancer Biol. Ther., 2005, 4, 585-592.

51- Hitchler, M. J.; Wikainapakul, K.; Yu, L.; Powers, K.; Attatippaholkun, W.; Domann, F. E. Epigenetic regulation of manganese superoxide dismutase expression in human breast cancer cells, Epigenetic, 2006, 1, 163171.

52- Hitchler, M. J.; Oberley, L. W.; Domann, F. E. Epigenetic silencing of SOD2 by histone modifications in human breast cancer cells, Free Radic. Biol. Med., 2008, 45,1573-1580.

53- Archer, S. L.; Marsboom, G.; Kim, G. H.; Zhang, H. J.; Toth, P. T.; Scensson, E. C.; Dyck, J. R.; Gomberg-Maitland, M.; Thebaud, B.; Husain, A. N.; Cipriani, N.; Rehman, J. Epigenetic attenuation of mitochondrial superoxide dismutase 2 in pulmonary arterial hypertension: a basis for excessive cell proliferation and new 
therapeutic target, Circulation, 2010, 121, 2661-2671.

54- Zhong, Q.; Kowluru, R. A. Epigenetic changes in mitochondrial superoxide dismutase in the retina and the development of diabetic retinopathy, Diabetes, 2011, 60, 1304-1313.

55- Hurt, E. M.; Thomas, S. B.; Peng, B.; Farrar, W. L. Molecular consequences of SOD2 expression in epigenetically silenced pancreatic carcinoma cell lines, Br. J. Cancer, 2007, 97, 1116-1123.

56- Laukkanen, M.O.; Mannermaa, S.; Hiltunen, M. O.; Aittomaki, S.; Airenne, K.; Janne, J.; Yla-Herttuala, S. Local hypomethylation in atherosclerosis found in rabbit ec-sod gene, Arterioscler. Thromb. Vasc. Biol., 1999, 19, 2171-2178.

57- Zelko, I. N.; Stepp, M. W.; Vorst, A. L.; Folz, R. J. Histone acetylation regulates cellspecific and interferon-gamma inducible ECSOD expression in human pulmonary arteries, Am. J. Respir. Cell. Mol. Biol., 2011; 45: 953 - 961.

58- Kikuchi, H.; Kuribayashi, F.; Kiwaki, N.; Tanami, Y.; Nakayama, T. GCN5 regulates the superoxide-generating system in leukocytes via controlling gp91-phox gene expression, J. Immunol., 2011, 186, 30153022.

59- Yu, Z.; Zhang, W.; Kone, B. C. Histone deacetylases augment cytokine induction of the iNOS gene, J. Am. Soc. Nephrol., 2002, 13, 2009 - 2017.

60- Yu, Z.; Kone, B. C. Targeted histone H4 acetylation via phosphoinosittide-3-kinase and p70s6-kinase-dependent pathways inhibits iNOS induction in mesangial cells, Am. J. Physiol. Renal. Physiol., 2006, 290, F496-502.

61- Xu, X. F.; Ma, X. L.; Shen, Z.; Wu, X. L.; Cheng, F.; Du Z. Epigenetic regulation of the endothelial nitric oxide synthase gene in persistent pulmonary hypertension of the newborn rat, J. Hypertens., 2010, 28, 2227 2235.

62- Falck, E.; Karlsson, S.; Carlsson, J; Helenius, G.; Karlsson, M.; Klinga-Levan, K. Loss of glutathione peroxidase 3 expression is correlated with epigenetic mechanism in endometrial adenocarcinoma, Cancer Cell Int., 2010,10, 46, 1-9.

63- Min, J. Y.; Lim, S. O.; Jung, G. Downregulation of catalase by reactive oxygen species via hypermethylation of $\mathrm{CpG}$ island II on the catalase promoter, FEBS Lett., 2010, 584, 2427-2432.

64- Quan, X.; Lim, S. O.; Jung, G. Reactive oxygen species downregulate catalase via methylation of a $\mathrm{CpG}$ Island in the Oct-1 promoter, FEBS Lett., 2011, 585, 3436-3441.

65- Hitcher, M. J.; Domann, F. E. Metabolic defects provide a spark for the epigenetic switch in cancer, Free Radic. Biol. Med., 2009, 47, 115-127.

66- Afanas'ev, I. Reactive oxygen species signaling in cancer: comparison with aging, Aging and Disease, 2011, 2, 219-230.

67- Luxen, S.; Belinsky, S. A.; Knaus, U. G. Silencing of DUOX NADPH oxidases by promoter hypermethylation in lung cancer, Cancer Res., 2008, 68,1037-1045.

68- Bhusari, S. S.; Dobosy, J. R.; Fu, V.; Almassi, N.; Oberley, T.; Jarrard, D. F. Superoxide dismutase 1 knockdown induces oxidative stress and DNA methylation loss in the prostate, Epigenetics, 2010, 5, 402-409.

69- Lim, S. O.; Gu, J. M.; Kim, M. S.; Kim, H.; Park, Y. N.; Park, C. K.; Cho, J. W.; Park, Y. M.; Jung, G. Epigenetic changes induced by reactive oxygen species in hepatocellular carcinoma: methylation of the E-cadherin promoter, Gastroenterology, 2008,135, 21282140.

70- Campos, A. C.; Molognoni, F.; Melo, F. H.; Galdieri, L. G.; Carneiro, C. R.; D’Almeida, V.; Correa, M.; Jasiulionis, M. G. Oxidative stress modulates DNA methylation during melanocyte anchorage blockade associated with malignant transformation, Neoplasia, 2007, 9,1111-1121.

71- Katayama, Y.; Takahashi, M.; Kuwayama, H. Helicobacter pylori causes runx3 gene methylation and its loss of expression in gastric epithelial cells, which is mediated by nitric oxide produced by macrophages, Biochem. Biophys. Res. Commun., 2009, 388, 496-500. 
72- Ruiz-Magana, M. J.; Rodrigues-Vargas, J. M.; Morales, J. C.; Saldivila, M. A.; SchulzeOsthoff, K.; Ruiz-Ruiz, C. The DNA methyltransferase inhibitors zebularine and decitabine induce mitochondria-mediated apoptosis and DNA damage in p53 mutant leukemic $\mathrm{T}$ cells, Int. J. Cancer, 2011, 10.1002/ijc.26107.

73- Han, Z. J.; Song, G.; Cui, Y.; Xia, H. F.; Ma, $\mathrm{X}$. Oxidative stress is implicated in arsenicinduced neutral tube defects in chick embryos, Int. J. Dev. Neurosci., 2011, 29, 673-680.

74- Zhou, J.; Bi, C.; Cheong, L. L.; Mahara, S.; Liu, S. C.; Tay, K. G.; Koh, T-L.; Yu, Q.; Chng, W-J. The histone methyltransferase inhibitor DZNep upregulates TXNIP, increases ROS production, and targets leukemia cells in AML, Blood, 2011, 118, 2830 - 2839.

75- Kim, H. S.; Patel, K.; Muldoon-Jacobs, K.; Bisht, K. S.; Aykin-Burns, N.; Pennington, J. ;; van der Meer, R.; Nguyen, P.; Savage, J.; Owens, K. M.; Vassilopoulos, A.; Ozden, O.; Park, S. H.; Singh, K. K.; Abdulkadir, S. A.; Spitz, D. R.; Deng, C. X.; Gius, D. SIRT3 is a mitochondria-localized tumor suppressor required for maintenance of mitochondrial integrity and metabolism during stress, Cancer Cell, 2010, 17, 41-52.

76- Lee, J. H.; Jeong, E. G.; Choi, M. C.; Kim, S. H.; Park, J. H.; Song, S. H.; Park, J.; Bang, Y. J.; and TY Kim, T. Y. Inhibition of histone deacetylase 10 induces thioredoxininteracting protein and causes accumulation of reactive oxygen species inSNU-620 human gastric cancer cells, Mol. Cells, 2010, 30, 107-112.

77- Agudelo, M.; Gandhi, N.; Saiyed, Z.; Pichili, V.; Thangavel, S.; Khatavkar, P.; Yndart, A.; Nair, M. Effects of alcohol on histone deacetylase 2 (HDAC2) and neuroprotective role of trichostatin A (TSA), Alcohol Clin. Exp. Res., 2011, 35, 1550-1556.

78- Johnston, R. W. Histone-deacetylase inhibitors: novel drugs for the treatment of cancer, Nat. Rev. Drug Discov., 2002, 1, 287299.
79- Miller, C. P.; Singh, M. M.; Rivera-Del Valle, N.; Manton, C. A.; Chandra, J. Therapeutic strategies to enhance the anticancer efficacy of histone deacetylase inhibitors, Biomed. Biotechol., 2011; 2011: 514261.

80- Ruefli, A. A.; Ausserlechner, M. J.; Bernhard, D.; Sutton, V. R.; Tainton, K. M.; Kofler, R.; Smyth, M. J.; Johnstone, R. W. The histone deacetylase inhibitor and chemotherapeutic agent suberoylanilide hydroxamic acid (SAHA) induces a cell-death pathway characterized by cleavage of Bid and production of reactive oxygen species, Proc. Natl. Acad. Sci. USA, 2001, 98, 1083310838.

81- Rosato, R. R.; Almenara, J. A.; Grant, S. The histone deacetylase inhibitor MS-275 promotes differentiation or apoptosis in human leukemia cells through a process regulated by generation of reactive oxygen species and induction of p21CIP1/WAF1 1, Cancer Res., 2003, 63, 3637-3645.

82- Lucas, D. M.; Davis, M. E.; Parthun, M. R.; Mone, A P.; Kitada, S.; Cunningham, K. D.; Flax, E. L.; Wickham, J.; Reed, J. C.; Byrd, J. C.; Grever, M. R. The histone deacetylase inhibitor MS-275 induces caspase-dependent apoptosis in B-cell chronic lymphocytic leukemia cell, Leukemia, 2004, 18, 12071214.

83- Rivera-Del Valle, N.; Gao, S.; Miller, C. P.; Fulbright, J.; Gonzales, C.; Sirisawad, M.; Steggerda, S.; Wheler, J.; Balasubramanian, S.; Chandra, J. PCI-24781, a novel hydroxamic acid HDAC inhibitor, exerts cytotoxicity and histone alteration via caspase-8 and FADD in leukemia cells, Int. J. Cell. Biol., 2010; 2010: 207420.

84- Pey, X. Y.; Dai, Y.; Grant, S. Synergistic induction of oxidative injury and apoptosis in human multiple myeloma cells by the proteasome inhibitor bortezomib and histone deacetylase inhibitors, Clin. Cancer Res., 2004, 10, 3839-3852. DOI: 10.1158/10780432.CCR-03-0561

85- Sato, T.; Suzuki, M.; Sato, Y.; Echigo, S.; Rikiishi, H. Sequence-dependent interaction between cisplatin and histone deacetylase 
inhibitors in human oral squamous cell carcinoma cells, Int. J. Oncol., 2006, 28, 1233-1241.

86- Kato, Y.; Salumbides, B. C.; Wang, X. F.; Qian, D. Z.; Williams, S.; Wei, Y.; Sanni, T. B.; Atadja, P.; Pili, R. Antitumor effect of histone deacetylase inhibitor LAQ824 in combination with 13-cis-retinoic acid in human malignant melanoma, Mol. Cancer Ther., 2007, 6, 70-81. DOI: 10.1158/15357163.MCT-06-0125

87- Miller, C. P.; Ban, K.; Dujka, M. E.; McConkey, D. J.; Munsell, M.; Palladino, M.; Chandra, J. NPI-0052, a novel proteasome inhibitor, induces caspase- 8 and ROSdependent apoptosis alone and in combination with HDAC inhibitors in leukemia cell, Blood, 2007, 110, 267-277. DOI: 10.1182/blood-2006-03-013128

88- Miller, C. P.; Rudra, S.; Keating, M. J.; Wierda, W. G.; Palladino, M.; Chandra, J. Caspase- 8 dependent histone acetylation by a novel proteasome inhibitor, NPI-0052: a mechanism for synergy in leukemia cells, Blood, 2009, 113, 4289-4299. DOI: 10.1182/blood-2008-08-174797

89- Donadelli, M.; Costanzo, C.; Beghelli, S.; Scupoli, M. T.; Dandrea, M.; Bonora, A.; Piacentini, P.; Budillon, A.; Caraglia, M.; Scarpa, A.; Palmieri, M. Synergistic inhibition of pancreatic adenocarcinoma cell growth by trichostatin A and gemcitabine, Biochim, Biophys. Acta, 2007, 1773, 1095106.

90- Seo, S. K.; Jin, H. O.; Lee, H. C.; Woo, S. H.; Kim, E. S.; Yoo, D. H.; Lee, S. J.; An, S.; An, S.; Rhee, C. H.; Hong, S. I.; Choe, T. B.; Park, I. C. Combined effects of sulindac and suberoylaninide hydroxamic acid on apoptosis induction in human lung cancer cells, Mol. Pharmacol., 2008, 73, 1005-1012. DOI: $10.1124 / \mathrm{mol} .107 .041293$

91- Vandermeers, F.; Hubert, P.; Delvenne, P.; Mascaux, C.; Crigoriu, B.; Burny, A.; Scherpereel, A.; Willems, L. Valproate, in combination with pemetrexed and cisplatin, provides additional efficacy to the treatment of malignant mesothelioma, Clin. Cancer
Res., 2009, 15, 2818-2828. DOI: 10.1158/1078-0432.CCR-08-1579

92- Nguyen, T.; Dai, Y.; Attkisson, E.; Kramer, L.; Jordan, N.; Nguyen, N.; Kolluri, N.; Kolluri, N.; Muschen, M.; Grant, S.; HDAC inhibitors potentiate the activity of the $\mathrm{BCR} / \mathrm{ABL}$ kinase inhibitor $\mathrm{KW}-2449$ in imatinib-sensitive or -resistant BCR/ABL+ leukemia cells in vitro and in vivo, Clin. Cancer Res., 2011, 17, 3219-3232.

93- Dai, Y.; кi M,; Dent, P.; Grant, S. Blockade of histone deacetylase inhibitor-induced Rel/p65 acetylation and NF-kappaB activation potentiates apoptosis in leukemia cells through a process mediated by oxidative damage, XIAP downregulation, and c-Jun Nterminal kinase 1 activation, Mol. Cell. Biol., 2005, 25, 5429-5444. DOI: 10.1128/MCB.25. 13.5429-5444.2005

94- Rosato, R. R.; Almenara, J. A.; Maggio, S. C.; Coe, S.; Atadja, P.; Dent, P.; Grant, S. Role of histone deacetylase inhibitor-induced reactive oxygen species and DNA damage in LAQ-24/fludarabine antileukemic interactions, Mol. Cancer Ther., 2008, 7, 3285-3297.

95- Yu, C.; Friday, B. B.; Lai, J.-P.; McCollum, A.; Atadja, P.; Roberts, L. R.; Adjei, A. A. Abrogation of MAPK and Akt signaling by AEE788 synergistically potentiates histone deacetylase inhibitor-induced apoptosis through reactive oxygen species generation, Clin. Cancer Res., 2007, 13, 1140-1148. DOI: 10.1158/1078-0432.CCR-06-1751

96- Yu, C.; Dasmahapatra, G.; Dent, P.; Grant, S. Synergetic interactions between MEK1/2 and histone deacetylase inhibitors in BCR/ABL+ human leukemia cells, Leukemia, 2005, 19, 1579-1589. DOI: 10.1038/sj.leu.2403868

97- Gao, N.; Rahmani, M.; Shi, X.; Dent, P.; Grant, S. Synergistic antileukemic interactions between 2-medroxyestradiol (2$\mathrm{ME})$ and histone deacetylase inhibitors involve Akt down-regulation and oxidative stress, Blood, 2006, 107, 241-249. DOI: 10.1182/blood-2005-06-2409

98- Dasmahapatra, G.; Lembersky, D.; Son, M. P.; Attkisson, E.; Dent, P.; Fisher, R. I.; Friedberg, J. W.,; Grant, S. Carfilzomib 
interacts synergistically with histone deacetylase inhibitors in mantle cell lymphoma cells in vitro and in vivo, Mol. Cancer Ther., 2011,10, 1686-1697. DOI: 10.1158/1535-7163.MCT-10-1108

99- Bhalla, S.; Balasubramanian, S.; David, K.; Sirisawad, M.; Buggy, J.; Mauro, L. PCI24781 induces caspase and reactive oxygen species-dependent apoptosis through NF$\{$ kappa\}B mechanisms and is synergistic with bortezomib in lymphoma cells, Clin. Cancer Res., 2009, 15, 3354-3365. DOI: 10.1158/1078-0432.CCR-08-2365

100- Meli, M.; Tolomeo, M.; Grifantini, M.; Mai, A.; Cappellacci, L.; Petrelli, R.; Rotili, D.; Ferro, A.; Saiko, P.; Szekeres, T.; Dusonchet, L. Histone deacetylase inhibition modulates deoxyribonucleotide pools and enhances the antitumor effects of the ribonucleotide reductase inhibitor 3'-C-methyladenosine in leukemia cells, Int. J. Oncol., 2011, 38, 14271436.

101- Feinberg, A. P.; Ohlsson, R.; Henikoff, S. The epigenetic progenitor origin of human cancer, Nat. Rev. Genetic., 2006, 7, 21-33. DOI: $10.1038 / \mathrm{nrg} 1748$

102- Cyr, A. R.; Domann, F. E. The redox basis of epigenetic modifications: from mechanisms to functional consequences, Antioxid. Redox. Signal., 2011,15, 551-589. DOI: 10.1089/ars.2010.3492

103- Ziech, D.; Franco, R.; Pappa, A.; Panayiotidis, M. I. Reactive oxygen species (ROS)--induced genetic and epigenetic alterations in human carcinogenesis, Mutat. Res., 2011, 711, 167-173. DOI: 10.1016/j.mrfmmm.2011.02.015

104- Smith, B. C.; Denu, J. M. Chemical mechanisms of histone lysine and arginine modifications, Biochim. Biophys. Acta, 2009, 1789, 45-57.

105- Li, X.; Chen, B. D. Histone deacetylase inhibitor M344 inhibits cell proliferation and induces apoptosis in human THP-1 leukemia cells, Am. J. Biomed. Sci., 2009, 1, 352-363. 